\title{
Smoking Cessation with E-Cigarettes in Smokers with a Documented History of Depression and Recurring Relapses
}

\author{
Pasquale Caponnetto $^{1,2}$, Riccardo Polosa ${ }^{1}$, Roberta Auditore ${ }^{2}$, Cristina Russo ${ }^{1}$, Davide Campagna ${ }^{1}$ \\ ${ }^{1}$ Smoking Prevention/Cessation Centre, A.O.U, Policlinico-V. Emanuele, University of Catania, Catania, Italy; ${ }^{2}$ Villa Chiara Com- \\ munity Therapeutic Rehabilitation Centre (CTA), Mascalucia (Catania), Italy. \\ Email: p.caponnetto@unict.it
}

Received February 24 ${ }^{\text {th }}$, 2011; revised April 16 ${ }^{\text {th }}$, 2011; accepted April 30 ${ }^{\text {th }}, 2011$.

\begin{abstract}
The association between nicotine dependence and affective disorders, particularly major depressive disorder (MDD), is well known with high prevalence rates being reported for smokers. The reason for this association is not clear, but, it has been argued that smoking may help individuals to cope with stress or medicate depressed mood. Smoking cessation programs are useful in helping smokers to quit, but smoking is a very difficult addiction to break, especially for people suffering from depression, and the need for novel and effective approaches to smoking cessation interventions for this special population is unquestionable. The e-cigarette is a battery-powered electronic nicotine delivery device (ENDD), which may help smokers to remain abstinent during their quit attempt. Here, we report for the first time objective measures of smoking cessation in two heavy smokers, suffering from depression, who experiment the e-cigarette.
\end{abstract}

Keywords: Smoking Cessation, Depression, Electronic Cigarette, Cigarette Smoking

\section{Introduction}

Cigarette smoke harms nearly every system of the human body, thus causing a broad range of diseases, many of which are fatal $[1,2]$. The risk of serious disease diminishes rapidly after quitting and life-long abstinence is known to reduce the risk of lung cancer, heart disease, strokes, chronic lung disease and other cancers $[3,4]$. Although evidence-based recommendations indicate that smoking cessation programs are useful in helping smokers to quit [5], smoking is a very difficult addiction to break particularly for people suffering from depression.

The association between nicotine dependence and affective disorders, particularly major depressive disorder (MDD), is well known with high prevalence rates being reported for smokers [6,7]. The reason for this association is not clear, but, it has been argued that smoking may help individuals to cope with stress [8] or medicate depressed mood [9]. Until recent years, the belief that a history of depression greatly decreases the likelihood of quitting smoking has been widely promoted [10]. It must be noted that the process of cessation itself produces withdrawal symptoms, which include a variety of mood disturbances and affective symptoms (depressed mood, anxiety, nervousness, restlessness, irritability, fatigue, and drowsiness); these are more pronounced in the days immediately following cessation and generally return to baseline levels within a month of continued abstinence. These differences in mood disturbance appear to be related to successful cessation as well [11]. Predictably, smokers reporting higher levels of negative mood and depressive symptoms were less likely to quit than were smokers with less mood disturbance [7]. Although it is generally assumed that a history of depression may be a barrier to quitting smoking, contradictory evidence also exists [12,13]. The meta-analysis by Hitsman et al. [12] shows that lifetime history of major depression does not appear to be an independent risk factor for cessation failure in smoking cessation treatment. Likewise, a recent paper from the Veterans Administration Normative Aging Study shows that the presence of depressive symptoms did not have a significant impact on smoking cessation [13]. Although there is little doubt that currently-marketed smoking cessation products increase the chance of committed smokers to stop smoking, they reportedly lack high levels of efficacy-particularly in the real life setting [14]. 
The need for novel and effective approaches to smoking cessation interventions for this special population is unquestionable. The e-cigarette is a battery-powered electronic nicotine delivery device (ENDD) resembling a cigarette designed for the purpose of nicotine delivery to the respiratory system, where nor tobacco nor combustion are necessary for its operation [8]. Consequently, it is likely that this product may be considered as a lower risk substitute for factory-made cigarettes. In addition, people report buying them to help quit smoking, to reduce cigarette consumption and to relieve tobacco withdrawal symptoms due to workplace smoking restrictions [9]. Besides delivering nicotine to the lung, e-cigarettes may also provide a coping mechanism for conditioned smoking cues by replacing some of the rituals associated with smoking gestures (e.g. hand-to-mouth action of smoking). For this reason, e-cigarettes may help smokers to remain abstinent during their quit attempt. To date there is no formal demonstrations supporting the efficacy of these devices in smoking cessation for people suffering from depression.

Here, we report for the first time objective measures of smoking cessation in two heavy smokers, suffering from depression, who experiment the e-cigarette.

\section{Case Report}

In this case series we describe two heavy smokers with an established history of depression who have been repetitively managed for nicotine dependence at our university clinic for smoking cessation (Centro per la Prevenzione e Cura del Tabagismo-CPCT; Università di Catania; Italy). At CPCT, smoking cessation programs are based on an adaptation from the Clinical Practice Guideline on Smoking Cessation of the US Department of Health and Human Services [5] and have been described previously in detail [15]. Staff at CPCT includes a dedicated team of clinical psychologists, psychiatrists, physicians, and nurses with at least 3-yr experience. Despite failing repeatedly our smoking cessation programs, these two individuals were able to quit tobacco smoking on their own by using e-cigarettes.

\subsection{Patient 1}

A 51-year-old engineer with a diagnosis of severe nicotine dependence attended our smoking cessation clinic in April 2006. He smoked 30 cigarettes/day (44 pack/yrs) with a significant level of nicotine dependence (Fagerstrom Test of Nicotine Dependence-FTND = 8). His eCO reading at baseline was $25.5 \mathrm{ppm}$. A history and diagnosis of major depression were reported. He was subjected to intensive treatment for nicotine dependence in April 2006 and subsequently in September 2007, July 2008 and May 2009. On each occasion, he was prescribed with an association of nicotine patches and bupropion and he was offered smoking cessation counseling throughout the program. Last relapse was noted on June 2009.

During a routine telephone follow-up in January 2010, he reported having quitted smoking on its own after taking up an e-cigarette. He was then invited to call at our clinic to collect more details and for further investigations. He told us he started experimenting with an e-cigarette (loaded with high nicotine concentration: 7.2 mg nicotine/cartridge) in August 2009. A few weeks later, he was able to discontinued tobacco smoking completely. He kept using his e-cigarette for another couple of months before stopping using the e-cigarette as well. Abstinence from tobacco smoking was then objectively assessed by measuring the concentration of exhaled breath carbon monoxide concentration (eCO); the measured $\mathrm{eCO}$ value was within the normal range $(\mathrm{eCO}=4$ ppm). He has been quitting tobacco smoking for approximately six months with no reported lapse/relapse during this period of time. The e-cigarette was well tolerated with no reported adverse effects.

\subsection{Patient 2}

A 50-year-old housewife with a diagnosis of severe nicotine dependence attended our smoking cessation clinic in June 2007. She smoked 20 - 30 cigarettes/day (29 pack/yrs) with a significant level of nicotine dependence (FTND = 8). Her eCO reading at baseline was $19.8 \mathrm{ppm}$. A history and diagnosis of major depression were reported. She was treated for nicotine dependence at our clinic in June 2007 and subsequently in October 2007 and January 2009. On each occasion, she was prescribed with an association of nicotine patches and bupropion and she was offered smoking cessation counseling throughout the program. Last relapse was noted on February 2009.

During a routine telephone follow-up in January 2010, she reported having quitted smoking on her own after taking up an e-cigarette. She was then invited to attend for a follow-up visit at our clinic, during which abstinence was reviewed objectively by measuring the concentration of eCO. She told us she started experimenting with an e-cigarette (loaded with high nicotine concentration: $7.2 \mathrm{mg}$ nicotine/cartridge) in April 2009. Three months later, she was able to discontinue tobacco smoking completely. She kept using the e-cigarette with high nicotine concentration for another month before switching to mentholated cartridges, which she now uses frequently during social events. Abstinence from tobacco smoking was confirmed objectively by the very low levels of eCO $(\mathrm{eCO}=2 \mathrm{ppm})$. She has been quitting tobacco smoking for approximately seven months with no reported lapse/relapse during this period of time. Overall, the e-cigarette was well tolerated with occasional dry 
cough being reported.

\section{Discussion}

The most important message from this case series is that these individuals were able to quit and to remain abstinent for at least 6 months after taking up an electronic cigarette. This is the first time that objective measures of smoking cessation are reported in smokers, suffering from depression, who quit after experimenting with the e-cigarette. This is quite outstanding in consideration of the fact that this result was accomplished by highly addicted smokers who repeatedly failed professional smoking cessation assistance without the support of recommended nicotine dependence treatments and smoking cessation counselling.

The remarkable success stories of these two smokers, suffering from depression, require justification. The widely acknowledged beneficial role of pharmacotherapy in smoking cessation is likely to be due to their ability to address the physical component of tobacco dependence. However, taking pills or patches for nicotine addiction is unlikely to resolve the psychological components (cognitive, social and behavioural) associated with tobacco dependence. As a matter of fact smoking is much more than the addicting effect of nicotine; the smoking habit is also the rituals that each smoker associates with his/her habit [6]. For example, smoking gestures (e.g. the tactile sensations of the cigarette and other sensations associated with smoking gestures) can play an important part in tobacco addiction as they are usually performed in a predictable, ritualistic manner that act to signal a mental context shift. When the smoker stops smoking, those rituals are no longer there, but the need for the ritual still exists and this is an important cause of relapse. Smoking cessation products cannot replace the rituals associated with the act of smoking. Counselling for smoking cessation is intended to help smokers in coping with this important aspect of their life by implementing personalized replacement rituals, but even counselling for smoking cessation lacks high levels of efficacy.

Therefore, it is likely that the smokers described in our case series coped successfully with the psychological components associated with their tobacco dependence by using a device resembling a cigarette, which-although being mainly designed for the purpose of nicotine delivery to the respiratory system-it has the additional advantage of being a valid substitute for the tactile sensations of the cigarette and other sensations associated with smoking gestures.

Although the present findings cannot be generalized, high quit rates would be desirable in a population that generally respond poorly to smoking cessation efforts like smokers suffering from depression. Larger con- trolled studies are needed to confirm this interesting findings, particularly for those smokers for whom handling and manipulation of their cigarettes play an important part of the ritual of smoking.

\section{Acknowledgements}

Riccardo Polosa is full Professor of Internal Medicine and he is supported by the University of Catania, Italy.

\section{REFERENCES}

[1] R. Doll, R. Peto, J. Boreham and I. Sutherland, "Mortality in Relation to Smoking: 50 Years' Observations on Male British Doctors,” British Medical Journal, Vol. 328, No. 7436, 2004, pp. 1519-1528. doi:10.1136/bmj.38142.554479.AE

[2] P. Boyle, N. Gray, J. Henningfield, J. Seffrin and W. Zatonski, "Tobacco and Public Health: Science and Policy,” Oxford University Press, Oxford, 2004.

[3] US Department of Health and Human Services, "The Health Benefits of Smoking Cessation,” DHHS Publication No. (CDC)90-8516, US Department of Health and Human Services, Public Health Service, Centers for Disease Control, Center for Chronic Disease Prevention and Health Promotion, Office on Smoking and Health, 1990.

[4] J. M. Lightwood and S. A. Glantz, "Short-Term Economic and Health Benefits of Smoking Cessation," Circulation, Vol. 96, No. 4, 1997, pp. 1089-1096.

[5] M. C. Fiore, C. R. Jaen, T. B. Baker, W. C. Bailey, N. Benowitz, S. J. Curry, et al., "Treating Tobacco Use and Dependence: 2008 Update,” US Department of Health and Human Services, Public Health Service, May 2008.

[6] N. Breslau, M. Kilbey and P. Andreski, "Nicotine Dependence and Major Depression," Archives of Genenal Psychiatry, Vol. 50, No. 1, 1993, pp. 31-35.

[7] R. F. Anda, D. F. Williamson, L. G. Escobedo, E. E. Mast, G. A. Giovino and P. L. Remington, "Depression and the Dynamics of Smoking," The Journal of the American Medical Association, Vol. 264, No. 12, 1990, pp. 1541-1545. doi:10.1001/jama.264.12.1541

[8] A. D. Revell, D. M. Warburton and K. Wesnes, "Smoking as a Coping Strategy,” Addictive Behaviors, Vol. 10, No. 3, 1985, pp. 209-224. doi:10.1016/0306-4603(85)90002-4

[9] L. S. Covey, A. H. Glassman and F. Stetner, "Major Depression Following Smoking Cessation," The American Journal of Psychiatry, Vol. 154, No. 2, 1997, pp. 263-265.

[10] A. H. Glassman, "Cigarette Smoking: Implications for Psychiatric Illness,” The American Journal of Psychiatry, Vol. 150, No. 4, 1993, pp. 546-553.

[11] P. Caponnetto and R. Polosa, "Common Predictors of Smoking Cessation in Clinical Practice,” Respiratory Medicine, Vol. 150, No. 4, 2008, pp. 546-553

[12] B. Hitsman, B. Borrelli, D. E. McChargue, B. Spring and R. Niaura, "History of Depression and Smoking Cessation Outcome: A Meta-Analysis,” Journal of Consulting 
and Clinical Psycholog, Vol. 71, No. 4, 2003, pp. 657-663. doi:10.1037/0022-006X.71.4.657

[13] T. Kinnunen, A. Haukkala, T. Korhonen, Z. N. Quiles, A. Spiro and A. J. Garvey, "Depression and Smoking Across 25 Years of the Normative Aging Study," International Journal of Psychiatry in Medicine, Vol. 36, No. 4, 2006, pp. 413-426. doi:10.2190/G652-T403-73H7-2X28

[14] G. Casella, P. Caponnetto and R. Polosa, “Therapeutic Advances in the Treatment of Nicotine Addiction: Present and Future,” Therapeutic Advances in Chronic Disease,
Vol. 1, No. 3, 2010, pp. 95-106. doi:10.1177/2040622310374896

[15] G. Piccillo, P. Caponnetto, S. Barton, C. Russo, A. Origlio, A. Bonaccorsi, A. D. Maria, C. Oliveri and R. Polosa, "Changes in Airway Hyperresponsiveness Following Smoking Cessation: Comparisons between Mch and AMP,” Respiratory Medicine, Vol. 102, No. 2, 2008, pp. 256-265. doi:10.1016/j.rmed.2007.09.004 